\title{
Time reduction to evaluate Pinus taeda seeds germination by time-to-event analysis
}

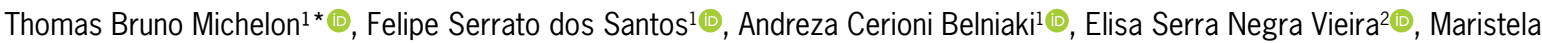 \\ Panobianco ${ }^{1}$ (1)
}

\author{
'Universidade Federal do Paraná - Depto. de Fitotecnia e \\ Fitossanidade - R. dos Funcionários, 1540 - 80035-050 - \\ Curitiba, PR - Brasil. \\ ²Embrapa Florestas, Estrada da Ribeira, km 111 - 83411- \\ 000 - Colombo, PR - Brasil. \\ *Corresponding author <thomasbrunomichelon@gmail.com>
}

Edited by: Jason N. James

Received April 01, 2021

Accepted August 19, 2021
ABSTRACT: The species Pinus taeda is largely used in intensive silviculture worldwide. This species has propagation through seeds, which requires determining seeds viability for their commercialization. The germination test recommended for this species usually requires up to 63 days to provide results on the quality of freshly harvested seeds, delaying commercialization and favoring contamination during the conduction of the test. The authors of this study aimed to establish the developmental stages of $P$. taeda seedlings to determine a criterion for interpreting the germination test with greater speed and efficiency to obtain results. The seeds were sown in transparent plastic boxes on two sheets of blotting paper and placed in a germinator at $22{ }^{\circ} \mathrm{C}$ with constant lighting. Five morphological stages of seedling development were defined with daily counts of the number of normal seedlings for each criterion, distribution in time, and the accumulated percentage of normal seedlings adjusted to time-to-event nonlinear regression. The new interpretation criterion proposed in this study is efficient, and $P$. taeda seedlings can be considered normal when cotyledon leaves differ by approximately $3 \mathrm{~mm}$ between the integument and hypocotyl, reducing the time to conduct the germination test by up to ten days compared to the criterion usually used in the routine analysis of seed laboratories.

Keywords: Pinaceae, viability, physiological quality, seedling development stages, nonlinear regression

\section{Introduction}

The species Pinus taeda has rapid growth and is largely used intensive silviculture worldwide for the production of wood-based products such as paper, cellulose, and energy matrix. Propagation of $P$. taeda is carried out through seeds; therefore, determining seed viability is essential to obtain quality seedlings, reducing transplanting costs in nurseries and it is a requirement for seed commercialization.

Some methods are used to determine the physiological quality of seeds of the genus Pinus, such as the spectroscopy-based reserve metabolite profiling analysis (Terskikh et al., 2005), which is still not viable on large scale, and the tetrazolium test, especially for the P. taeda species (ISTA, 2020; Santos et al., 2019). The germination test, however, is the only standard test available to determine the viability of $P$. taeda seeds (ISTA, 2020).

The germination test for $P$. taeda is considerably time-consuming, requiring 28 days to obtain the result and this time can be extended for another 14 days if necessary, totaling 42 days (ISTA, 2020). Moreover, a precooling treatment $\left(5-10^{\circ} \mathrm{C}\right.$ on a moistened substrate) is recommended for freshly harvested seeds for a period of 21 days. Thus, the entire viability evaluation can be extended for up to 63 days, considering the time to perform the germination test. This time period is to ensure that the seedlings reach the normal seedling stage, which represents the end of the test.

A seedling is considered normal when it presents intact essential structures (well developed shoots and roots and without atrophy), with damages in less than $50 \%$ of the tissue and only secondary infections. Additionally, the interpretation of a germination test should be performed based on the minimum conditions for seedling development and organization, which are necessary to originate a normal plant (Marcos-Filho, 2016; ISTA, 2020). In this sense, the duration of the test is related to the criteria established for normal seedling (Rosa et al., 2010; Guimarães et al., 2013).

The long duration of the test impairs the release of results, favors the occurrence of material contamination (Rosa et al., 2010), and hinders the routine of laboratories in terms of equipment use. In this study, we aimed to establish the developmental stages of $P$. taeda seedlings to determine a criterion to interpret the germination test with greater speed and efficiency to obtain the results.

\section{Materials and Methods}

The analyses were carried out in Curitiba, Paraná State, Brazil, using $P$. taeda seeds with thousand-seed weight of $24 \mathrm{~g}$, orthodox seeds, and classified as tested seeds (i.e. forestry seeds collected from genetically selected matrices approved by a certifying company). The seeds were produced in Rio Negrinho (Santa Catarina State, Brazil $-26^{\circ} 24^{\prime} \mathrm{S}, 49^{\circ} 35^{\prime} \mathrm{W}, 792 \mathrm{~m}$ a.s.l.) (Figure 1) and with endogenous dormancy already overcome by cold storage at $5{ }^{\circ} \mathrm{C}$. Moreover, the seeds were disinfected with $1 \%$ sodium hypochlorite for $3 \mathrm{~min}$, washed in distilled water, and dried on paper towels at room temperature for $30 \mathrm{~min}$.

For the germination tests, eight replications of 25 seeds each were sown on top of sterilized blotting paper (autoclave at $200{ }^{\circ} \mathrm{C}$ for $50 \mathrm{~min}$ ) on disinfected 


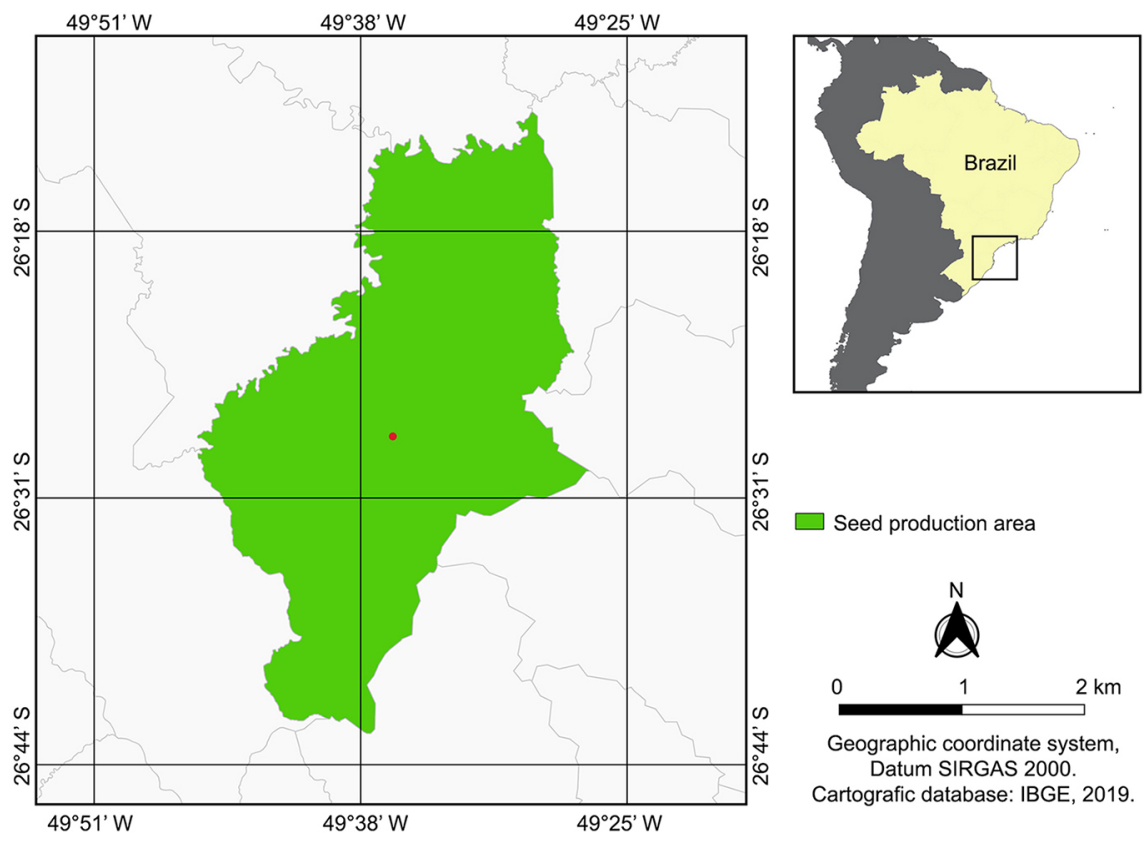

Figure 1 - Location of the municipality of Pinus taeda seed production - Rio Negrinho, Paraná State, Brazil.

transparent plastic boxes $(11.0 \times 11.0 \times 3.5 \mathrm{~cm})$ and moistened with $2-3$ times the substrate weight in water. The seeds were taken to a Mangelsdorf-type germinator chamber at $22^{\circ} \mathrm{C}$, with the presence of constant light, as indicated by ISTA for the species (ISTA, 2020).

Five developmental stages were defined: (S1) root protrusion - seed with a root of approximately $1 \mathrm{~mm}$; (S2) hypocotyl growth; (S3) appearance of cotyledon leaves; (S4) cotyledon leaves with a differentiation cleft of approximately $3 \mathrm{~mm}$ (new criterion proposed); and (S5) adhered or loose integument (criterion used in the routine analysis of laboratories, called original criterion).

All seeds $(8 \times 25)$ from the germination test were monitored from their demarcated position in the germination box to identify the time needed for each seed to reach the pre-established stages. The average time for the seed to reach each of the five evaluated stages was calculated at the end of the test measured from the time necessary for each seed to reach each defined stage.

\section{Statistical analysis}

The germination behavior was analyzed by nonlinear regression for each criterion of normal seedling (stages S4 and S5). The model choice and parameters estimation were based on the time-to-event analysis, which was chosen because it provides more reasonable inferences considering that the germination event did not occur at the specific time of evaluation, but during the interval between evaluations. It also considers the possibility of germination after the end of the experiment. These characteristics described by Onofri et al. (2010) and Ritz et al. (2013) correspond to the experimental characteristics.
Thus, three models based on distributions were considered: log-logistic, log-normal, and Weibull model. Each model with three parameters, which are respectively given by:

$F(t)=\frac{d}{1+\exp [b\{\log (t)-\log (e)]\}}=\frac{d}{1+\left(\frac{t}{e}\right)^{b}} ;$

$F(t)=d \Phi(b(\log (x)-\log (e))) ;$

$F(t)=d \exp (-\exp (b(\log (x)-e)))$,

where $F(t)$ is the fraction of germinated seeds between time interval $t, d$ is the parameter referring to the total germination, $b$ is the slope of the curve, and $e$ is the time needed to germinate $50 \%$ of the total germination.

The model selection was based on the Akaike information criterion (AIC), which penalizes models with high complexity or poorly adjusted, defined by AIC $=-2$ $\log L+2 p$, where $p$ is the number of parameters of the model and $\log L$ is the logarithm value of the maximized likelihood under each model (Akaike, 1974). The goodness of fit was evaluated graphically from the observed versus the predicted values (Onofri et al., 2018).

The period for germination stabilization was estimated considering the time to obtain $95 \%$ of the maximum number of normal seedlings at the end of the test for stages S4 (new proposed criterion for normal seedling) and S5 (original criterion for normal seedling). This value was considered because of the model characteristic, which considers the occurrence of $100 \%$ of germination at an indefinite time. A completely randomized design was used and the statistical procedures were conducted 
using $\mathrm{R}$ Development Core Team ( $\mathrm{R}$ Foundation for Statistical Computing, version 3.5.2).

\section{Results and Discussion}

The monitoring of the germination process of $P$. taeda seeds and the observation of the main morphological changes of the seedlings allowed establishing the respective stages of seedling development and the approximate time after sowing to reach each stage (Table 1).

The seed germination process starts with soaking (Marcos-Filho, 2016); however, it is not visible for the establishment of an evaluation standard because $P$. taeda seeds do not swell. The beginning of seedling development is marked by root protrusion (Souza, 2006) and the first stage (S1) (Figure 2A) was defined when it reached about $1 \mathrm{~mm}$, that is, about 3-4 days after sowing. The second stage (S2) was observed from 5-6 days after sowing, with the hypocotyl appearance, visually differentiated from the primary root because of its brown color (Figure 2B).

The third stage (S3) started at nine days after sowing with the appearance of the differentiation cleft of cotyledon leaves (Figure 2C). The fourth stage (S4) occurred at 10-11 days, with the differentiated cotyledon leaves approximately $3 \mathrm{~mm}$ long (Figure 2D), which is the new criterion proposed for normal seedlings. The last stage (S5) was the criterion used in the routine analysis of laboratories for normal seedling (original) and it occurred on average at 16 days after the test was started, with developed cotyledon leaves, integument slightly adhered (Figure 2E) or loose, and aciculae distanced and completely expanded (Figure 2F).

The difference between the average time for seedlings to reach the proposed new criterion (S4: 10-11 days) and the original criterion adopted in the routine analysis of laboratories for the species under study (S5: 16 days) was 5-6 days. The time required to stop the appearance of normal seedlings (stabilization period), estimated by the regression model, was 23 days for S5 and 13 days for S4, showing that the choice of the germination test at a normal seedling stage prior (S4) to the original (S5) the experiment can be finished 10 days before. Guimarães et al. (2013) worked with Coffea arabica seedlings and managed to reduce the germination test from 30 to 16 days by adopting a stage before the recommended criterion of normal seedling for the species, demonstrating the possibility to obtain the seed viability faster.
Reducing the period of conducting the germination test increases efficiency in the routine analysis of laboratories due to a reduction of time to use of the equipment. It also allows the analyst to save time, who concentrates the readings at a shorter interval. Moreover, companies in the seed sector can streamline the decisionmaking processes regarding the harvested and marketed batches (Reis et al., 2010; Tomaz et al., 2015).

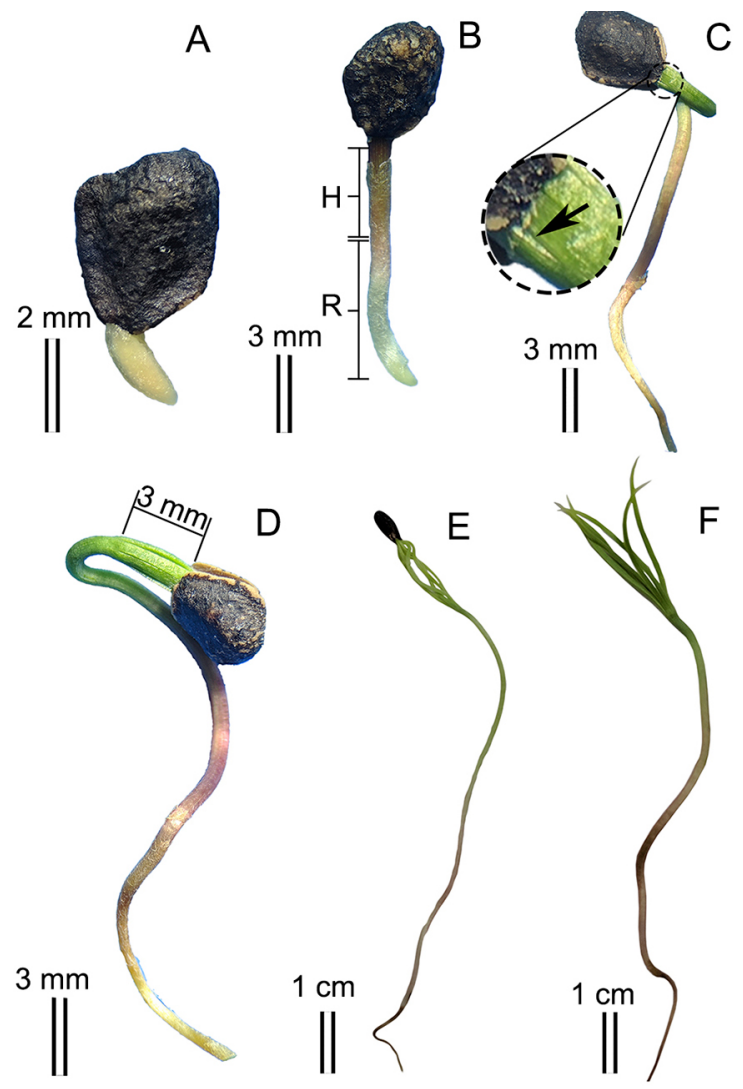

Figure 2 - Developmental stages of seedlings of Pinus taeda. A = root protrusion (stage $\mathrm{S} 1$ ); $\mathrm{B}=$ hypocotyl growth $(\mathrm{H}$ indicates the region of the hypocotyl and $\mathrm{R}$ the root region) (stage S2); $\mathrm{C}$ $=$ appearance of cotyledonary leaves with enlarged detail (arrow indicates differentiation of leaves) (stage 3); $D=$ differentiated cotyledonary leaves approximately $3 \mathrm{~mm}$ between the tegument and hypocotyl (stage S4); $\mathrm{E}=$ seedling with fully developed cotyledonary leaves and adhered tegument (stage S5); F = seedling with fully developed cotyledonary leaves and loose tegument (stage S5).

Table 1 - Morphological stages of seedling development of Pinus taeda, description and approximate number of days after sowing to reach each stage of development.

\begin{tabular}{llc}
\hline Stages & \multicolumn{1}{c}{ Description } & Mean time (days) \\
\hline S1 & Root protrusion approximately 1 mm long & $3-4$ \\
S2 & Hypocotyl and root differentiation & $5-6$ \\
S3 & Emergence of differentiated cotyledonary leaves & 9 \\
S4 & Differentiated cotyledonary leaves approximately 3 mm between the tegument and hypocotyl & $10-11$ \\
S5 & Fully developed cotyledonary leaves, with adhered or loose tegument & 16 \\
\hline
\end{tabular}


The maximum number of normal seedlings at stage S4 was observed at ten days after sowing, whereas the maximum number of normal seedlings considering the criterion adopted in the routine analysis of laboratories (stage S5) occurred at 14 and 19 days, indicating the need for intermediate readings (Figure 3). Therefore, the adoption of stage $\mathrm{S} 4$ as the final moment to evaluate the number of normal seedlings has operational advantages in the routine of a laboratory, as it requires less frequency of evaluations (Guimarães et al., 2013; Tomaz et al., 2016).

The three parameters log-logistic regression (42 degrees of freedom and $p$-value $<0.001$ for each parameter) shows a better fit by the lower AIC value (1727.5) in comparison to the Weibull (1741.4) and Lognormal distribution (1754.5), as well a good fit by a graphical comparison of observed and predicted values for stages S4 and S5 (Figure 4). Guimarães et al. (2013) and Tomaz et al. $(2015,2016)$ have also performed this analysis as a selection criterion in different experiments. According to the slope parameter (b parameter), the evaluation of the number of normal seedlings at stage S4 resulted in a slope coefficient of -13.648 , while the same evaluation at stage S5 showed a slope coefficient of -8.719 (Table 2), meaning that stage S4 has higher slopes (lower value) to the plateau than stage S5. In other words, the coefficients ratio showed that the time between the occurrence of the first and last normal seedling, considering stage S4, occurred approximately 1.6 times faster than in stage S5.

Because the period to reach stage $\mathrm{S} 4$ is shorter, seedlings tend to reach the criterion more uniformly, that is, there is less variance of the average compared to stage S5. Guimarães et al. (2013) found similar results. Thus, the choice of stage S4 not only reduces the duration of the experiment, but it also shortens the interval between the appearance of the first and the last normal seedlings.

According to the asymptotes estimated by the model, represented by parameter $d$ (Table 2), the proposed evaluation criterion in stage S4 presented $75 \%$ viability of the seed batch, whereas the evaluation at

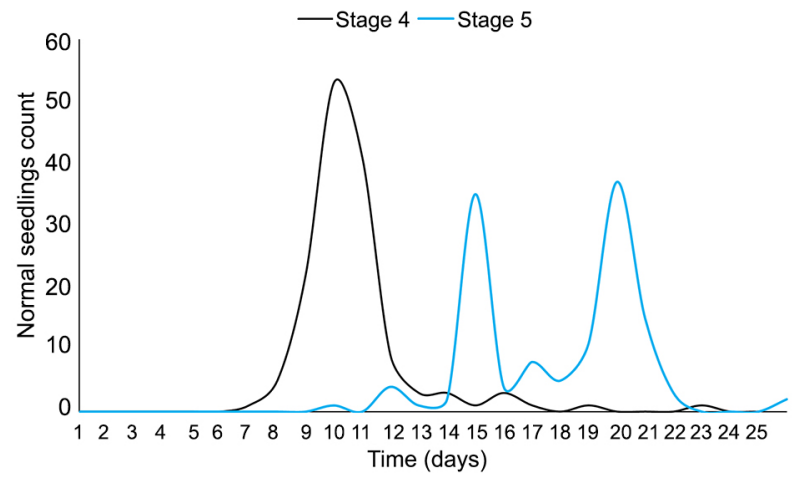

Figure 3 - Number of normal $P$. taeda seedlings as a function of days after sowing in the proposed new criterion (S4) and in the criteria adopted in the routine laboratory analysis (S5). stage S5 showed viability of $68 \%$ of the batch, which is below the minimum standard of commercialization of $70 \%$ in Brazil adopted for P. taeda seeds (MAPA, 1984). Abnormalities occurred before stage S4, characterized by root atrophy with callus formation, seedlings with only the aerial part, that is, the early cotyledons emerged directly from the integument, with no roots, and seedlings with twisted shoots and strangulation by the perisperm. No seedling abnormalities were found between the proposed new criterion (S4) and that adopted in the routine analysis of laboratories (S5). The variation in viability was due to the prolonged time between stages, which favored the attack of microorganisms from secondary infections in seedlings considered normal under the proposed criterion (S4).

The longer the germination test, the greater the chances of pathogen occurrences, such as Fusarium spp., which is common in P. taeda seeds. Furthermore, the recommendation to perform the test on paper facilitates fungal dissemination, which may be a problem for species

Table 2 - Germination rate - slope (b), total germination in proportion - asymptote (d) and time in days to reach $50 \%$ of maximum germination (T50) - inflection point (e) parameters estimated from the curves for the S4 and S5 evaluation stage.

\begin{tabular}{lcc}
\hline Parameters & Estimate & Standard Error \\
\hline $\mathrm{b}_{\mathrm{s4}}{ }^{*}$ & -13.65 & 1.01 \\
$\mathrm{~b}_{\mathrm{s} 5}$ & -8.72 & 0.73 \\
$\mathrm{~d}_{\mathrm{s4}}$ & 0.75 & 0.03 \\
$\mathrm{~d}_{\mathrm{s} 5}$ & 0.68 & 0.04 \\
$\mathrm{e}_{\mathrm{s4}}$ & 10.88 & 0.11 \\
$\mathrm{e}_{\mathrm{s} 5}$ & 16.51 & 0.31 \\
\hline
\end{tabular}

${ }^{*}$ S4 = Stage 4; S5 = Stage 5.

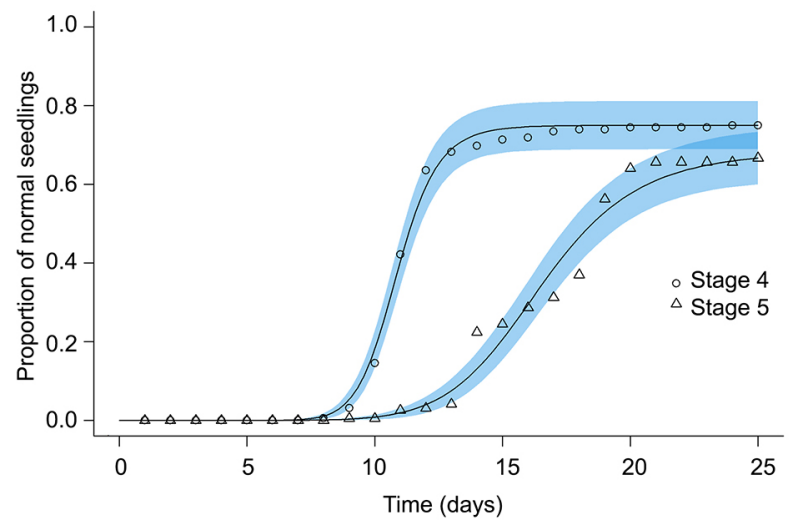

Figure 4 - Nonlinear three parameters log-logistic regression adjusted to the percentages of normal $P$. taeda seedlings evaluated over time in the proposed new criterion (S4) and in the criteria adopted in the routine laboratory analysis (S5). The line represents nonlinear regression and the blue band refers to the $95 \%$ confidence interval.

Stage $4-F(t)=\frac{0.75}{1+\left(\frac{t}{10.88}\right)^{-13.65}} ;$ Stage $5-F(t)=\frac{0.68}{1+\left(\frac{t}{16.51}\right)^{-872}}$. 
that require a prolonged time to reach the normal seedling standard (Silva et al., 2017; ISTA, 2020). The adoption of a criterion that reduces the duration of the germination test reduces pathogen attacks in seedlings with all necessary structures to be considered normal (Rosa et al., 2010, Caldeira et al., 2015).

Some studies were carried out to obtain seed viability in a practical way either by the adequacy of alternative techniques, such as the tetrazolium test (Calles et al., 2020) or by reducing the duration of the germination test or through seed treatments (Caldeira et al., 2015; Tomaz et al., 2016). Although these techniques are effective, some require higher technification of the laboratory and specialized personnel, generating extra costs and making evaluation difficult. The improvement of the germination test methodology of $P$. taeda through the adoption of a criterion for analysis in the previous morphological stage, as routinely adopted, is a simple form of implementation with a significant capacity to reduce the evaluation period, without compromising the results and allowing speed in the commercialization of seeds and higher efficiency in the routine analysis of laboratories. Future research should test more and less vigorous seeds to evaluate the potential reduction of the germination test, evidenced in the current study.

\section{Conclusion}

The new interpretation criterion proposed in the present study (S4) is efficient. Pinus taeda seedlings can be considered normal when cotyledon leaves differ by approximately $3 \mathrm{~mm}$ between the integument and hypocotyl, which reduces the duration of the germination test by up to ten days compared to the criterion usually used in the routine analysis of seed laboratories (S5).

\section{Acknowledgments}

To the Coordination for the Improvement of Higher Education Personnel (CAPES - Finance Code 001), for providing a scholarship to the first author and the company Klabin for donating the seeds to the experiment.

\section{Authors' Contributions}

Conceptualization: Panobianco, M.; Vieira, E.S.N.; Santos, F.S. Data acquisition: Michelon, T.B. Data analysis: Michelon, T.B. Design of methodology: Panobianco, M.; Vieira, E.S.N. Writing and editing: Michelon, T.B.; Panobianco, M.; Vieira, E.S.N.; Belniaki, A.C.

\section{References}

Caldeira, C.M.; Carvalho, M.L.M.; Oliveira, J.A.; Kataoka, V.Y.; Freire, A.I. 2015. Reduced time for evaluation of the germination test for sunflower seeds. Journal of Seed Science 37: 70-75.
Calles, T.; Walle, E.M.; Kruse, M. 2020. Viability of and germination test conditions for Schoenocaulon officinale seeds. Journal of Crop Improvement 34: 637-643.

Guimarães, G.C.; Rosa, S.V.F.; Coelho, L.S.F.; Veiga, A.D.; Clemente, A.C.S. 2013. Minimum period to assess the potential of germination of coffee seeds. Journal of Seed Science 35: 347352.

International Seed Testing Association [ISTA]. 2020. International Rules for Seed Testing. ISTA, Bassersdorf, Germany.

Marcos-Filho, J. 2016. Seed Physiology of Cultivated Plants. 2 ed. ABRATES, Londrina, PR, Brazil.

Ministério da Agricultura, Pecuária e Abastecimento [MAPA]. 1984. Ordinance $\mathrm{n}^{\circ} 18$, January $25,1984=$ Portaria $\mathrm{n}^{\circ}$ 18, de 25 de janeiro de 1984. MAPA, Brasília, DF, Brazil. Available at: https://www.gov.br/agricultura/ptbr/assuntos/insumos-agropecuarios/insumos-agricolas/ sementes-e-mudas/publicacoes-sementes-e-mudas/ PortariaN18de25dejaneirode1984_Florestais_Padres.pdf (in Portuguese).

Onofri, A.; Gresta, F.; Tei, F. 2010. A new method for the analysis of germination and emergence data of weed species. Weed Research 50: 187-198.

Onofri, A.; Benicasa, P.; Mesgaran, M.B.; Ritz, C. 2018. Hydrothermal-time-to-event models for seed germination. European Journal of Agronomy 101: 129-139.

Reis, L.S.; Araújo, E.F.; Dias, D.C.F.S.; Sediyama, C.S.; Meireles, R.C. 2010. LERCAFE: new test to estimate the germination of the coffee tree seeds (Coffea arabica L.). Revista Brasileira de Sementes 32: 9-16 (in Portuguese, with abstract in English).

Ritz, C.; Pipper, C.B.; Streibig, J.C. 2013. Analysis of germination data from agricultural experiments. European Journal of Agronomy 45: 1-6.

Rosa, S.D.V.F.; Mcdonald, M.B.; Veiga, A.D.; Vilela, F.L.; Ferreira, I.A. 2010. Saging coffee seedling growth: a rationale for shortening the coffee seed germination test. Seed Science and Technology 38: 421-431.

Santos, F.S.; Vieira, E.S.N.; Panobianco, M. 2019. Tetrazolium test for Pinus taeda: preparation, staining, and seed viability classes. Pesquisa Agropecuária Brasileira 54: 1-5.

Silva, T.W.R.; Santos, A.F.; Auer, C.G.; Tessmann, D.J. 2017. Detection methods, transmission and pathogenicity of Fusarium spp in Pinus taeda seeds. Ciência Florestal 27: 73-84 (in Portuguese, with abstract in English).

Souza, L.A. 2006. Morphology and Plant Anatomy: Cell, Tissues, Organs and Seedling. = Morfologia e Anatomia Vegetal: Célula, Tecidos, Órgãos e Plântula. UEPG, Ponta Grossa, PR, Brazil (in Portuguese).

Terskikh, V.V.; Feurtado, J.A.; Borchardt, S.; Giblin, M.; Abrams, S.R.; Kermode, A.R. 2005. In vivo C-13 NMR metabolite profiling: potential for understanding and assessing conifer seed quality. Journal of Experimental Botany 56: 2253-2265.

Tomaz, D.A.; Martins, C.; Silva, Z.; Vieira, D. 2016. Period of time taken by Brachiaria humidicola (Rendle) Scheweick seed to complete germination. Semina: Ciência Agrária 37: 693-700.

Tomaz, C.D.A.; Martins, C.C.; Feis, M.; Sanches, G.; Vieira, R.D. 2015. Time reduction for surinam grass seed germination test. Ciência e Agrotecnologia 39: 488-497. 